DOI: http://dx.doi.org/10.18203/2320-1770.ijrcog20163426

Research Article

\title{
Severe anemia and adverse pregnancy outcome
}

\author{
Chandrika S.* \\ Department of Obstetrics and Gynaecology, ESIC, Gulbarga, Karnataka, India
}

Received: 28 July 2016

Accepted: 28 August 2016

\section{*Correspondence:}

Dr. Chandrika S.

E-mail: drchandrika.s@gmail.com

Copyright: (C) the author(s), publisher and licensee Medip Academy. This is an open-access article distributed under the terms of the Creative Commons Attribution Non-Commercial License, which permits unrestricted non-commercial use, distribution, and reproduction in any medium, provided the original work is properly cited.

\section{ABSTRACT}

Background: Anaemia is commonest medical disorder in pregnancy with $88 \%$ prevalence in India mainly due to ignorance, poverty and gender bias $40-60 \%$ of maternal deaths in developing countries. The aim of the study was to determine the association between severe anemia, maternal and perinatal complications.

Methods: Case control study was done in department of obstetrics and gynecology, Government Medical College Nagpur, India from September 2011 to February 2012. 50 pregnant women, admitted for delivery and having severe anemia were studied and compared with 100 non anemic women of similar demographic features. Maternal and perinatal complications were observed. Pearson, chi-square and Fischer exact tests were used to calculate significance of results.

Results: Of the severely anemic mothers, $36 \%$ babies were low birth weight $(\mathrm{p}=0.042)$ and $20 \%$ were small for gestational age $(\mathrm{p}=0.026)$, as compared to $18 \%$ and $10 \%$ of controls, respectively.

Conclusions: Severe maternal anemia carries significant risk of hemorrhage and infection in the mother. It is also associated with preterm birth, low birth weight.

Keywords: Severe anemia, Hemorrhage, Preterm birth, Low birth weight

\section{INTRODUCTION}

Anemia is commonest medical disorder in pregnancy with $88 \%$ prevalence in India mainly due to ignorance, poverty and gender bias $40-60 \%$ of maternal deaths in developing countries. ${ }^{1}$ It causes direct as well as indirect deaths from cardiac failure, hemorrhage, infection and pre eclampsia. ${ }^{2}$ It is defined by WHO as haemoglobin level less than 11 grams \% in pregnancy. It is divided in to three degree mild degree (9.0-10.9 gm\%), moderate degree (7.0-8.9 gm\%) and severe degree $(<7.0 \mathrm{gm} \%)$. It carries a lot of threats to the mother as well as baby. ${ }^{3}$ Current knowledge indicates that iron deficiency anemia in pregnancy is a risk factor for preterm delivery and subsequent low birth weight, and possibly for inferior neonatal health. ${ }^{4}$ Data are inadequate to determine the extent to which maternal anemia might contribute to maternal mortality. ${ }^{5}$ This deserves further exploration because of the tendency of infants to develop complications. Pregnant women with significant anemia may have an increased risk for poor pregnancy outcomes, particularly if they are anemic in the first trimester. ${ }^{6}$ The aim of the study was to determine the association between severe anemia, maternal and perinatal complications

\section{METHODS}

Case-control study was done at Department of Obstetrics and Gynaecology, GMC, Nagpur, India from September 2011 to November 2011. Study population of 100 (50 cases and 50 controls) were taken for the study. All patients admitted for delivery with $\mathrm{hb} \%<7 \mathrm{~g} / \mathrm{dl}$ were taken as inclusion criteria. Population having mild and moderate anemia (8-10 g/d), K/c/o haemogobinopathes like thalesemia, antipartum hemorrhage due to placenta previa, hemolytic anemia like SCD were excluded from the study.

50 pregnant women, admitted for delivery, having severe anemia were studied and compared with 100 non-anemic women of similar demographic features. Maternal and 
perinatal complications were observed, pearson, chisquare and fischer exact tests were used to calculate significance of results.

\section{RESULTS}

There were 1082 deliveries at GMC Nagpur, India. 725 (69\%) women had anaemia and 53 (6.9\%) had severe anemia.

Table 1: Characteristics of cases and controls of patients.

\begin{tabular}{|lll|}
\hline Characteristics & Cases & Controls \\
\hline Booked patients & 12 & 32 \\
\hline Unbooked & 38 & 18 \\
\hline Emergency admission & 40 & 26 \\
\hline OPD admission & 10 & 24 \\
\hline$<20$ year old & 6 & 5 \\
\hline$>20$ year old & 43 & 45 \\
\hline Primigravida & 17 & 8 \\
\hline Mutigravida & 33 & 26 \\
\hline Gestational age $<37$ week & 17 & 8 \\
\hline Gestational age $>37$ week & 33 & 42 \\
\hline Mean Hb\% & $6.2 \pm 0.6$ & $116 \pm 0.6$ \\
\hline Mean bood loss & $427 \pm 386$ & $252 \pm 128$ \\
\hline Blood transfusion $<5$ points & 33 & 1 \\
\hline Blood transfusion $1-5$ & 17 & 0 \\
\hline No blood transfusion & 0 & 49 \\
\hline Hospitaisation $<8$ days & 26 & 42 \\
\hline Hospitalization $>8$ days & 24 & 8 \\
\hline
\end{tabular}

Table 2: Maternal complications.

\begin{tabular}{|llcllll|}
\hline Complications & Cases & $\%$ & Controls & $\%$ & P-value \\
\hline $\begin{array}{l}\text { Post-partum } \\
\text { haemorrhage }\end{array}$ & 17 & 34 & 2 & 4 & 0.001 \\
\hline $\begin{array}{l}\text { Abruption } \\
\text { placenta }\end{array}$ & 5 & 10 & 3 & 6 & 0.712 \\
\hline $\begin{array}{l}\text { Wound } \\
\text { infection }\end{array}$ & 9 & 18 & 1 & 2 & 0.02 \\
\hline $\begin{array}{l}\text { Maternal } \\
\text { morbidity }\end{array}$ & 24 & 48 & 5 & 10 & 0.024 \\
\hline Maternal death & 4 & 8 & 0 & 0 & 0.126 \\
\hline
\end{tabular}

Post-partum hemorrhage occurred in 34\% (17) of cases as compared to $4 \%$ (2) of controls $(\mathrm{p}=0.001)$. Frequency of infection of surgical wound was $10 \%$ (5) in cases and $2 \%$ (1) in controls $(\mathrm{p}=0.002)$. Preterm birth was seen in $34 \%$ (17) cases and $16 \%$ (8) controls $(p=0.036)$. Of the severely anemic mothers, $36 \%$ (18) babies were low birth weight $(p=0.042)$ and $20 \%$ (10) were small for gestational age $(\mathrm{p}=0.026)$, as compared to $18 \%$ and $10 \%$ of controls, respectively. Frequency of maternal mortality was $8 \%$ (4) in cases and none in controls $(p=0.002)$. Morbidity was $28 \%$ (14). Perinatal death was seen in $4 \%$ (2) cases and none in controls $(\mathrm{p}=0.036)$.
Table 3: Perinatal complications.

\begin{tabular}{|llllll|}
\hline Complications & Cases & $\%$ & Controls & $\%$ & P-value \\
\hline Preterm birth & 17 & 34 & 8 & 16 & 0.036 \\
\hline $\begin{array}{l}\text { low birth } \\
\text { weight infants }\end{array}$ & 18 & 36 & 9 & 18 & 0.042 \\
\hline $\begin{array}{l}\text { Small for } \\
\text { gestational age } \\
\text { infants }\end{array}$ & 10 & 20 & 5 & 10 & 0.26 \\
\hline $\begin{array}{l}\text { APGAR score } \\
<7\end{array}$ & 4 & 08 & 2 & 04 & 0.67 \\
\hline In-utero death & 1 & 02 & 2 & 04 & 1 \\
\hline Perinatal death & 2 & 04 & 0 & 00 & 0.036 \\
\hline
\end{tabular}

\section{DISCUSSION}

Ali AAA, et al conducted retrospective case-control study at Kassala hospital, eastern Sudan. pregnant women with severe anemia $(\mathrm{Hb})<7 \mathrm{~g} / \mathrm{dl}, \mathrm{n}=303)$ who delivered from January 2008 to December 2010 with 2.3 times risk of LBW, 3.4 times risk of preterm, 4.3 times risk stillborns, concluded as greater the severity of the anaemia during pregnancy, the greater the risk of preeclampsia, preterm delivery, LBW and stillbirth. ${ }^{7}$

Karaflahin E, et al studied assosiation between maternal anaemia and perinatal outcome at Gulhane Military Medical Academy, Department of Obstetrics and Gynecology, Ankara. ${ }^{8}$

Kavle JA, et al found strong association of severe anemia with post-partum hemorrhage. Wandabwa $\mathrm{J}$ et al has also indicated chronic anemia as a predictor for post-partum hemorrhage.

\section{CONCLUSION}

Severe maternal anaemia caries significant risk of hemorrhage, infection, morbidity and mortality in mother. It also associated with preterm birth, low birth weight and perinatal mortality.

\section{Funding: No funding sources}

Conflict of interest: None declared

Ethical approval: The study was approved by the Institutional Ethics Committee

\section{REFERENCES}

1. World Health Organization. WHO Global Database. Geneva: WHO, 1997.

2. Sarin AR. Severe anemia in pregnancy, recent experience. Int J Gynecology Obstetric. 1995;50:459.

3. Brabin L, Nicholas S, Gogate A, Karande A. A high prevalence of anemia among women in Mumbai, India. Food Nutr Bull. 1998;19:205-9. 
4. Marhatta R. Study of anemia in pregnancy and its outcome in Nepal Medical College Teaching Hospital, Kathmandu, Nepal. Nepal Med Coll J. 2007;9:270-4.

5. Gregory P, Taslim A. Health status of Pakistani population: a health profile and comparison with the United States. Am J Public Health. 2001;91:93-8.

6. Bhatt R. Maternal mortality in India-FOGSI-WHO Study. J Obstet Gynecol Ind. 1997;47:207-14.
7. Ali AA, Dam I. Anaemia and stillbirth in Kassala hospital, eastern Sudan. J Trop Pediatr. 2011;57(1):62-4.

8. Karaflahin E, Ceyhan ST, Goktolga U, Keskin U, Bafler S. Maternal anemia and perinatal outcome. Perinatal J. 2007;15(3):129.

9. Kavle JA. Maternal anemia and blood loss at child birth and postpartum in Zanzibar, Tanzania. Baltimore, MD: Bloomberg School of Public Health, Johns Hopkins University, 2005:204.

Cite this article as: Chandrika S. Severe anemia and adverse pregnancy outcome. Int J Reprod Contracept Obstet Gynecol 2016;5:3475-7. 